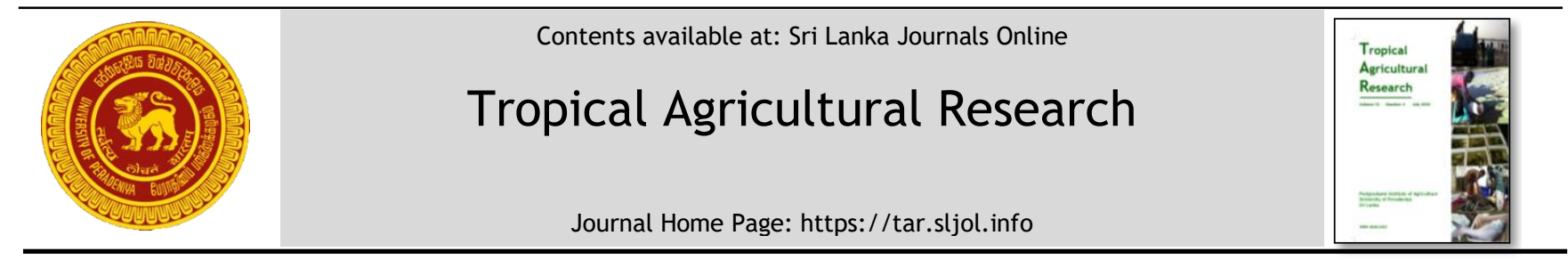

\title{
Microcrystalline Cellulose as Reinforcing Agents for Polypropylene Composites
}

A. Ratnakumar ${ }^{1}$, W.S.M. Rathnayake ${ }^{2}$, L. Karunanayake3 ${ }^{3}$, A.M.P.B. Samarasekara ${ }^{1 *}$ and D.A.S. Amarasinghe ${ }^{1}$

${ }^{1}$ Department of Materials Science and Engineering, Faculty of Engineering, University of Moratuwa, Moratuwa, Sri Lanka

${ }^{2}$ Department of Chemistry, Faculty of Applied Sciences, University of Sri Jayewardenepura, Nugegoda, Sri Lanka

${ }^{3}$ Department of Polymer Science, Faculty of Applied Sciences, University of Sri Jayewardenepura, Nugegoda, Sri Lanka

ARTICLE INFO

\section{Article history:}

Received: 14 August 2019

Accepted: 23 October 2019

Revised version received: 25 May 2020

Available online: 01 July 2020

\section{Keywords:}

Composite

Microcrystalline cellulose

Polypropylene

Reinforcement

\section{Citation:}

Ratnakumar, A., Rathnayake, W.S.M.,

Karunanayake L., Samarasekara A.M.P.B.

and Amarasinghe D.A.S. (2020).

Microcrystalline Cellulose as Reinforcing

Agents for Polypropylene Composites.

Tropical Agricultural Research, 31(3):

106-114.

DOI: http://doi.org/10.4038/tar.v31i3.8401

Ratnakumar, A.

https://orcid.org/0000-0001-7489-2732

\begin{abstract}
Microcrystalline cellulose (MCC) in its micrometric dimensions has gained a surge of interest in polymer reinforcement. This paper examines empirically the properties of MCC reinforced polypropylene (PP) composites varying the MCC loading from 0-5\%. Mechanical, thermal and physical properties were characterized using universal testing machines, shore D hardness tester, TGA, FTIR and XRD machines. The experimental results highlighted that the reinforcement of PP matrix with MCC, improved the properties of the composite gradually as the MCC loading increased. Tensile, hardness and impact properties were improved by $5 \%, 8 \%$ and 51\%, respectively for 5\% MCC reinforced PP composite. Therefore, these notable results exhibit the potential of reinforcement of PP matrix with MCC.
\end{abstract}

\footnotetext{
${ }^{*}$ Corresponding author: banduamp@gmail.com
} 


\section{INTRODUCTION}

There has been extensive work done throughout the industry in reinforcing polymer composites with fibers achieving a unique combination of both phases with a great versatility, tailoring better mechanical properties as well as higher performance. Recently emphasis has shifted from glass or carbon fiber reinforcement to natural fiber reinforced composites to abate the dependence of petroleum based products, focusing on more environmentally friendly low carbon foot print products (Samarasekara et al., 2012a; Samarasekara et al., 2014a; Samarasekara and Jayasuriya, 2014b; Samarasekara et al., 2015). Thus, many industries including automotive and aerospace industries have engrossed themselves in using more natural fiber reinforced polymer composites with the advantages of light weight, low density, nontoxicity, non-corrosiveness together with positive impacts on environment (Begum and Islam 2013; Kumar et al., 2017).

A variety of natural fibers have been used to supplement synthetic fibers including kenaf, jute, hemp, sisal and cellulose with their abundant availability, low cost, end-of-life degradability, high toughness and low energy usage in production (Joshi et al., 2004; Samarasekara et al., 2012b; Samarasekara et al., 2012c; Samarasekara et al., 2014; Liu et al., 2017). Being the most available natural polymer on earth cellulose has become one of the major candidates in fabricating polymeric substances. Many research communities have been making efforts on upgrading the properties of cellulose using different isolation methods initiating to diverse dimensions in micrometric and nanometric range and aspect ratios (Lu et al., 2014).

Sri Lanka has a high potential for cultivation and processing of a variety of crops leading to a considerable percentage of biodegradable agricultural wastes giving no commercial use but environmental pollution. From these superfluous agricultural wastes, cellulose can be extracted easily as a value-added product with variety of advantages. Microcrystalline cellulose (MCC) which can be isolated from native cellulose has attracted enormous interest in producing micro-composites. The interest arose from the extraordinary capacity of microscale reinforcement with a high degree of ordered crystalline regions, high surface area for interfacial bonding with polymer matrix as well as high mechanical strength and stiffness prior to cellulose (Yue, 2011; Sofla et al., 2016). MCC has lateral dimensions smaller than the wavelength of visible light making MCC free of light scattering. Thus MCC is ideal in fabricating transparent polymeric matrices (Zampaloni et al., 2007).

Polypropylene (PP) is one of the most versatile and widely used thermoplastic polyolefin used in many industries due to its low production cost, recyclability, transparency, ability to blend easily and reinforce and low density (Sain et al., 2016; Amir et al., 2017). However, due to its moderate mechanical properties the durability of the final products has become low. Therefore, to compete with engineering polymers, PP chain reinforcement with natural fibers were introduced, leading to better mechanical, thermal and physical properties (Nanayakkara et al., 2017; Rajapaksha et al., 2017; Kahawita et al., 2018).

This project mainly focused on fabrication of MCC in PP matrix to upgrade the thermal, mechanical and physical properties of the final ecologically innocuous, green MCC-PP composite.

\section{MATERIALS AND METHODS}

\section{Materials}

Homopolymer Polypropylene (TASNEE PP H4260M) and white crystalline MCC were used as received from The National Petrochemical Industrialization Marketing Cooperation, Saudi Arabia and Sisco Research Lab Pvt. Ltd., India, respectively.

\section{Fabrication of composites}

Homopolymer PP was compounded with different loadings $(0,1,2,3,4$ and $5 \%)$ of MCC to study the property variation with MCC loading. In an internal mixer (MX300-TQ) PP was added and mixed for 5 minutes at $180{ }^{\circ} \mathrm{C}$ 
at $65 \mathrm{rpm}$ with Banbury type rotors. Then appropriate amounts of MCC were added and compounded with PP for another 8 minutes at $180{ }^{\circ} \mathrm{C}$. Compounded samples were compression moulded at $180{ }^{\circ} \mathrm{C}$ for 5 minutes at $10 \mathrm{MPa}$ pressure and demoulded after the cooling process. Five samples were prepared from each composition.

\section{RESULTS AND DISCUSSION}

\section{FTIR Analysis}

Figure 1 shows the FTIR analysis (Thermo Scientific, USA, Nicolet IS10) of pure MCC, neat PP and PP-MCC 5\% composite. Pure MCC contained a broad $\mathrm{OH}$ stretching band at 3320 $\mathrm{cm}^{-1}, \mathrm{H}-\mathrm{O}-\mathrm{H}$ bending of absorbed water at $1644 \mathrm{~cm}^{-1}$ and C-O stretching vibration of cellulose backbone at $1025 \mathrm{~cm}^{-1}$. FTIR spectroscopy of MCC also contained characteristic bands at 1363, 1314 and 1201 $\mathrm{cm}^{-1}$ due to $\mathrm{OH}$ in plane bending (Akhtar et al.,
2016; Wei et al., 2017). C-O-C asymmetric stretching, $\mathrm{C}-\mathrm{O}$ stretching at $\mathrm{C} 6$, ring stretching in plane, $\mathrm{CH}_{2}$ symmetric bending, and $\mathrm{CH}$ stretching in methyl and methylene group at 897, 1059, 1111, 1430 and $2902 \mathrm{~cm} \mathrm{-1}^{-1}$, respectively suggesting that the MCC comprised of cellulose I structure. Moreover, $\mathrm{OH}$ stretching band at $3320 \mathrm{~cm}^{-1}$ and $\mathrm{OH}$ out of plane bending at $700 \mathrm{~cm}^{-1}$ confirmed that MCC sample contained a higher percentage of cellulose I- $\beta$ (Lu and Hsieh, 2010).

Four characteristic bands of neat PP were also present in PP-MCC composite as well. $\mathrm{CH}_{3}$ asymmetric and symmetric stretching vibrations, $\mathrm{CH}_{2}$ asymmetric and symmetric stretching vibrations were obtained at 2950, 2880, 2915 and $2845 \mathrm{~cm}^{-1}$ respectively (Morent et al., 2008). Bands attributed at 998 and $844 \mathrm{~cm}^{-1}$ confirmed the most stable confirmation of $3_{1}$ helix structure in isotactic PP structure (Andreassen, 1999).

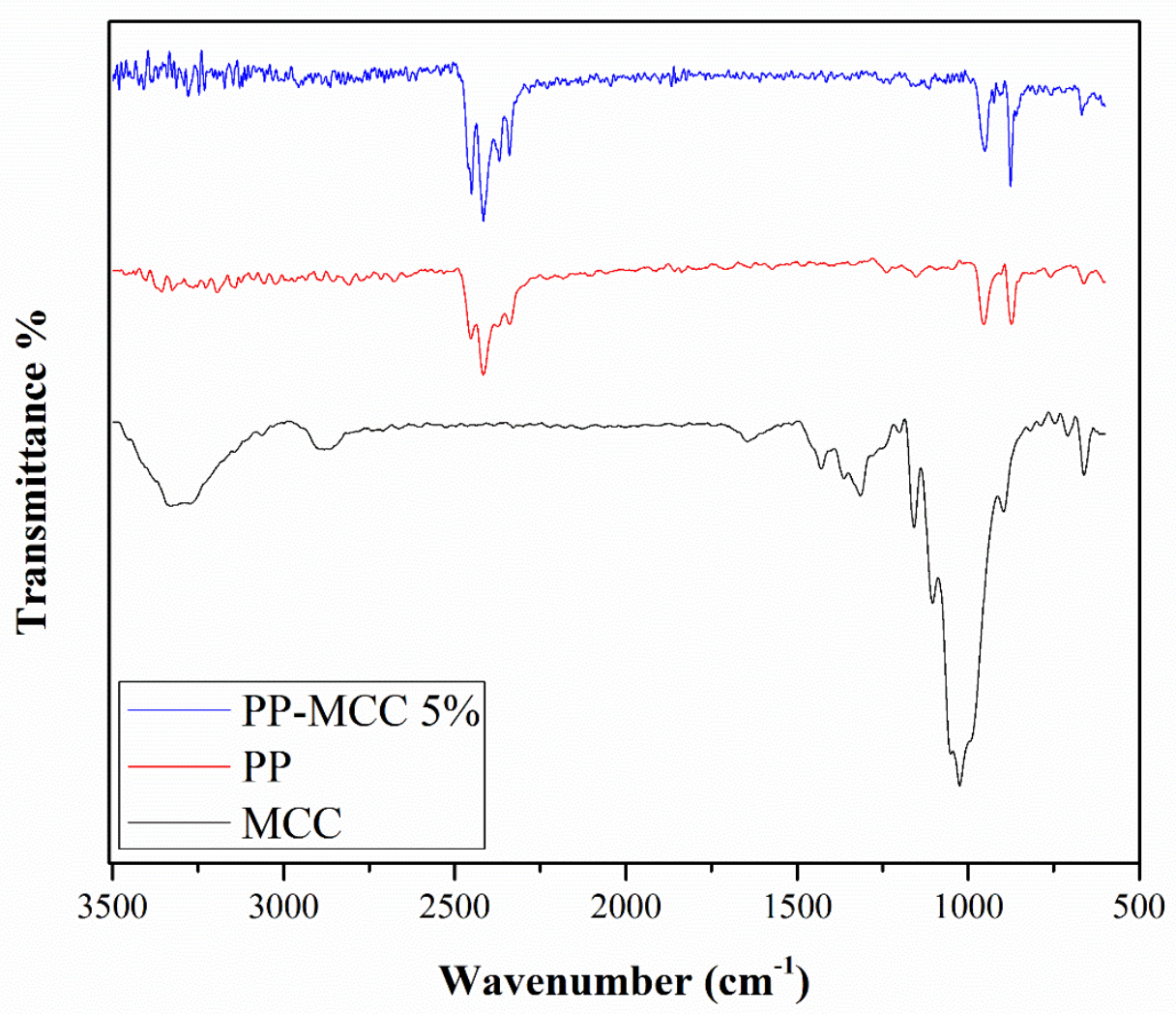

Figure 1. FTIR spectra of MCC, PP and PP-MCC 5\% composite 


\section{XRD Analysis}

XRD (Rigaku Ultima IV, USA) diffractogram of pure MCC showed a characteristic pattern of peaks at $14.9,16.4,22.5$ and $34.5^{\circ}$ attributed to (101), (101'), (002) and (040) diffraction planes of cellulose I respectively, as shown in Figure 2 (Lu and Hsieh, 2010). Occurrence of a more intense sharper peak for (002) suggested the higher degree of crystallinity as well as the higher percentage of cellulose I- $\beta$ structure (Poletto et al., 2013; Lee et al., 2014). Seven characteristic diffraction planes were introduced for both neat and PP composite at $14.3,16.3,18.6,21.5,22.1,25.6$ and $28.8^{\circ}$ for (110), (300), (130), (131+041), (060+150) and (220), respectively (Achaby et al., 2012). Absence of (300) plane at $16.3^{\circ}$ in composite diffractogram suggested that the incorporation of MCC into PP matrix induces changes in crystal structure of PP (Wang and Sheng, 2005).

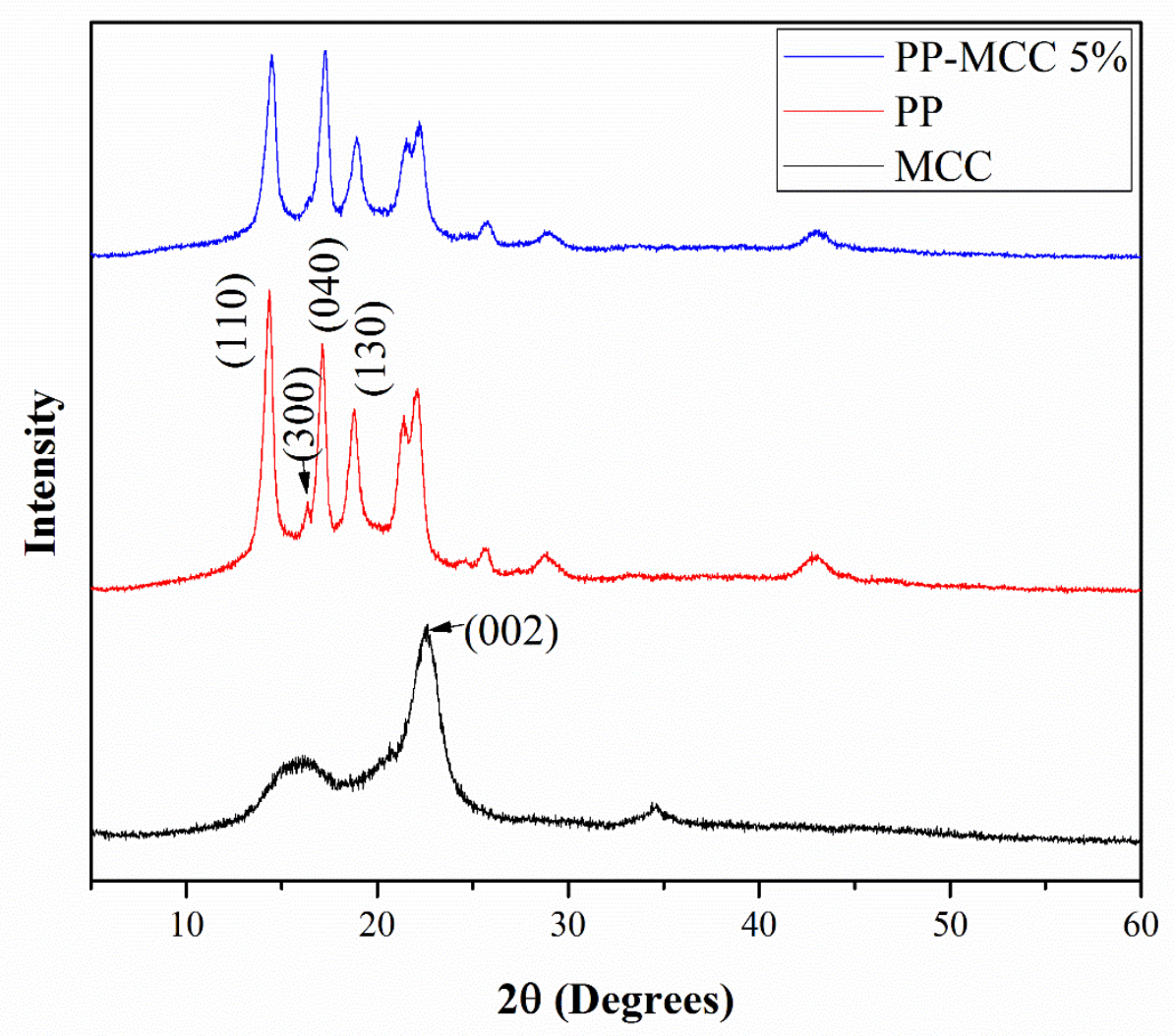

Figure 2. X-ray Diffractogram of MCC, PP and PP-MCC 5\% composite

\section{TGA Analysis}

Thermal stability variation of neat PP with the incorporation of MCC in composites were analyzed using thermogravimetric graphs using SDT Q600, USA (Quick Start software) (Figure 3). Single step degradation for neat PP showed at $434{ }^{\circ} \mathrm{C}$. As PP is reinforced with $5 \%$ MCC degradation shifted to a higher a temperature of $455{ }^{\circ} \mathrm{C}$ implying that MCC reinforcement improved the thermal stability of neat PP matrix (Canetti et al., 2006; Bikiaris et al., 2008). 


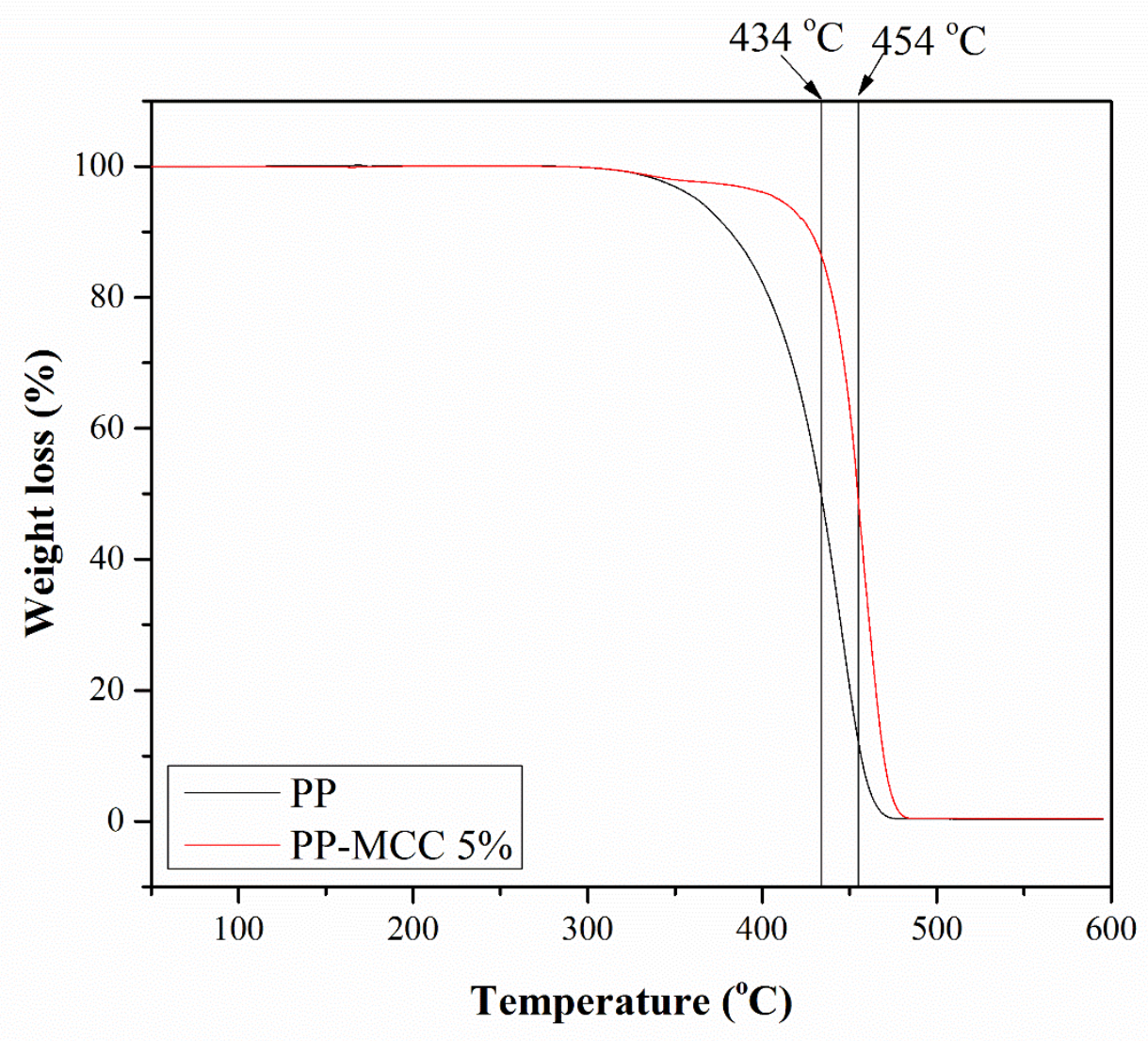

Figure 3. TGA curves of PP and PP-MCC 5\% composite

\section{Mechanical Properties}

\section{Tensile testing}

Universal tensile testing machine (Hounsfield) was used to observe the tensile strength of the composites. Average tensile strength of neat PP was marked at 27.24 MPa which was gradually increased with the addition of MCC (Figure 4). Maximum tensile strength, $28.65 \mathrm{MPa}$ was obtained for $5 \%$ MCC incorporation in PP composites. These results implied that as PP matrix reinforced with stiff MCC, the resistance to break at tension increased as well.

\section{Impact testing}

Izod Impact tester (HUNG TA Instrument Co. Ltd, Taiwan, HT-8041B) was used to characterize the impact strength. Impact strength variation (Figure 5) in PP composites showed that more energy can be absorbed prior to the fracture by the PP composite as the MCC loading increased. Thus, impact strength of neat PP was improved from $6.85 \mathrm{kJm}^{-2}$ to $10.40 \mathrm{kJm}^{-2}$ with the fabrication of $5 \%$ MCC in PP composite.

\section{Hardness testing}

Hardness (Shore D durometer, Teclock, GS702N) of MCC reinforced PP composites (Figure 6) showed higher values than neat PP (61.5). Gradual increment of shore D hardness in MCC-PP composites maximized to 66.5 with the addition of 5\% MCC in PP due to its higher reinforcement and decrement in PP chain flexibility. 


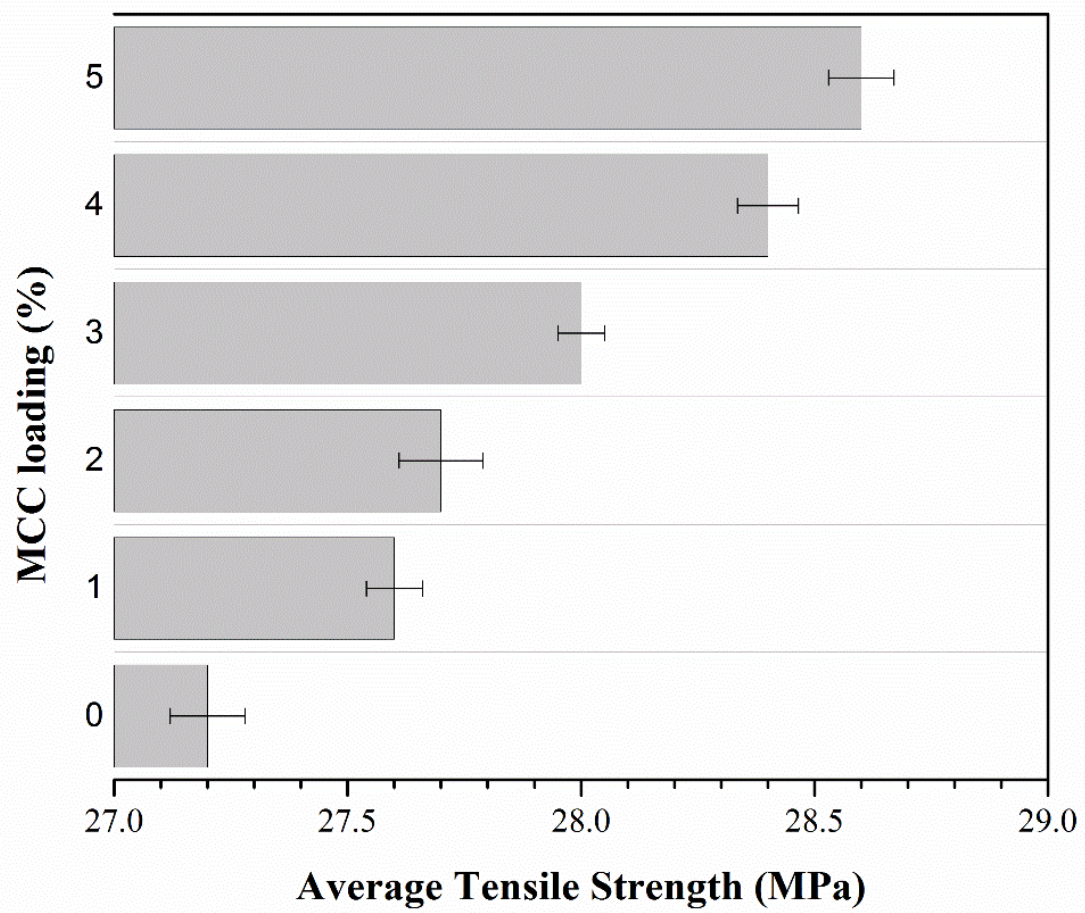

Figure 4. Average Tensile strength variation with respect to MCC loading

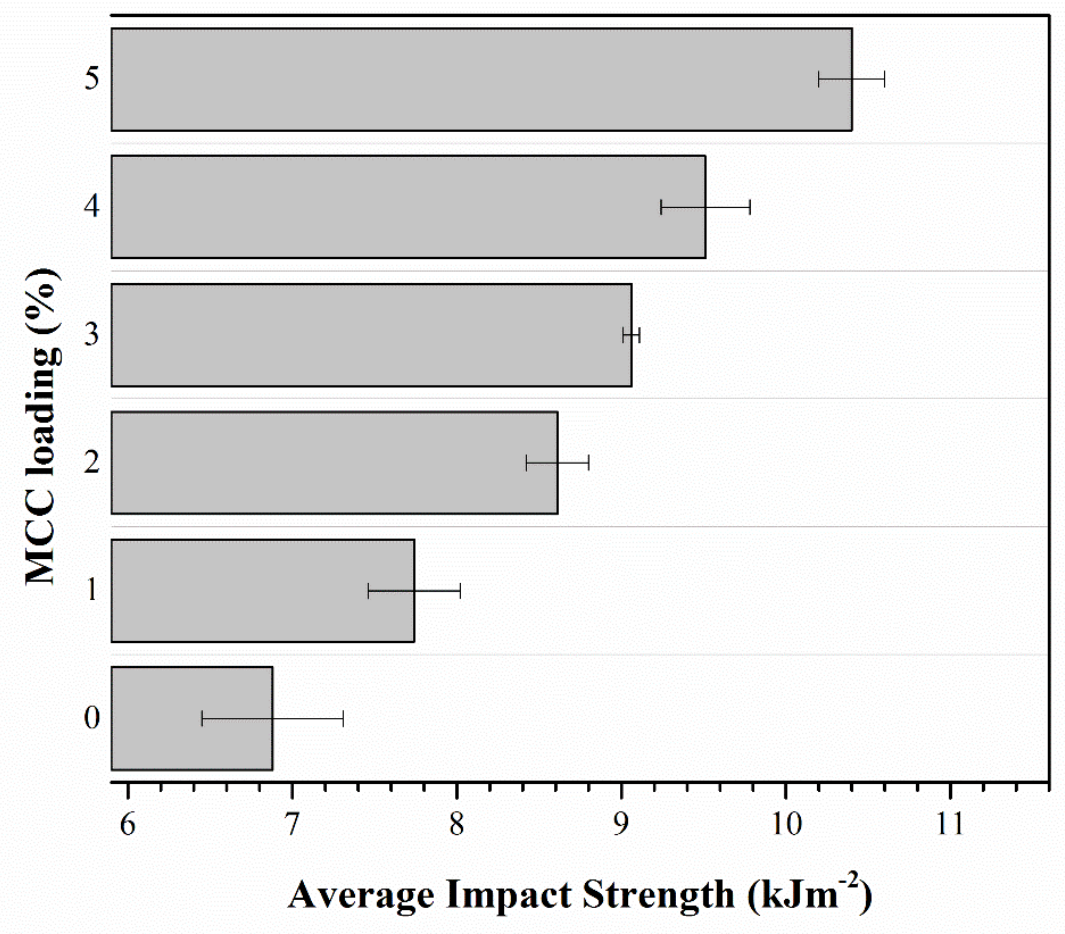

Figure 5. Average Impact strength variation with respect to MCC loading 


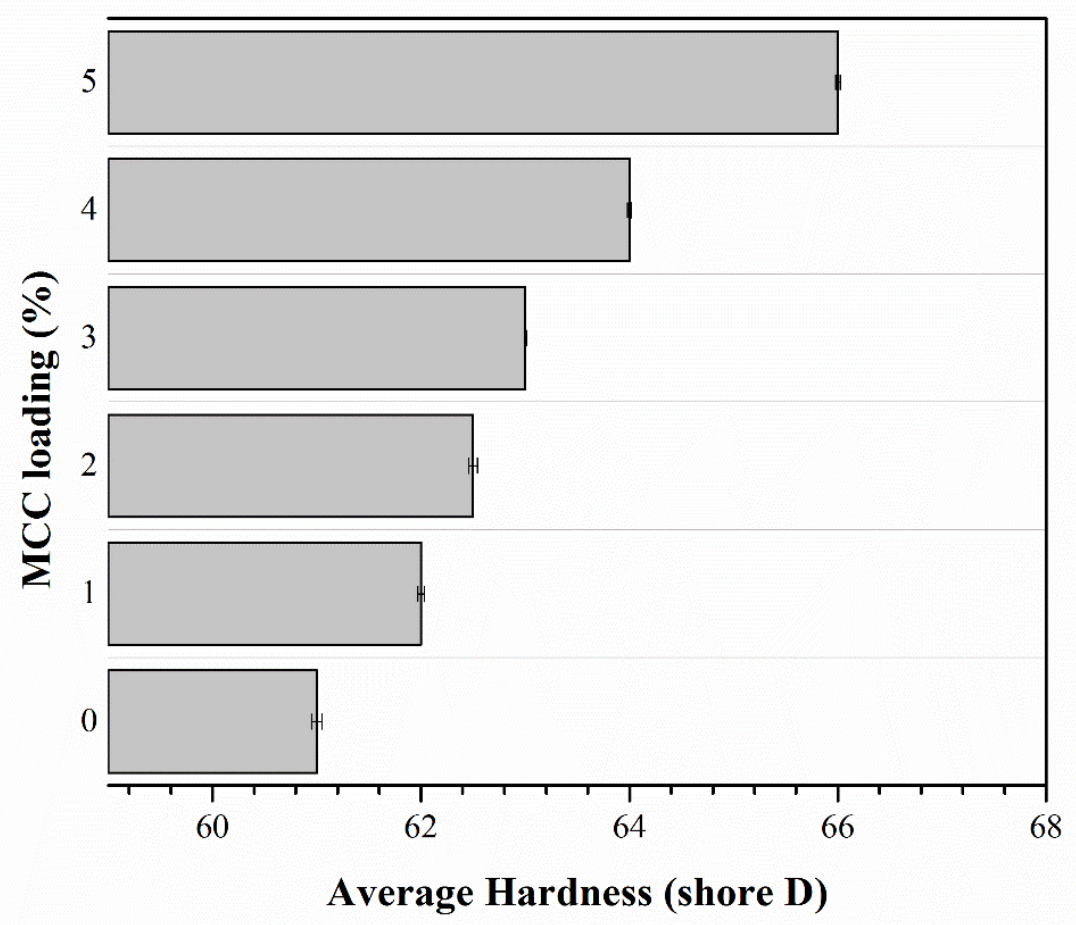

Figure 6. Average Hardness variation with respect to MCC loading

\section{CONCLUSIONS}

The experimental results showed a greater improvement in thermal and mechanical properties with the fabrication of MCC in PP matrix. Tensile, hardness and impact properties improved by $5 \%, 8 \%$ and $51 \%$, respectively in 5\% MCC reinforced PP

\section{REFERENCES}

Achaby, M.E., Arrakhiz, F.E., Vaudreuil, S., Kacem Qaiss, A., Bousmina, M. and Fassi-Fehri O. (2012). Mechanical, thermal, and rheological properties of graphene-based polypropylene nanocomposites prepared by melt mixing. Polymer Composites. 33, 733744.

Akhtar, M.N., Sulong, A.B., Radzi, M.K.F., Ismail, N.F., Raza, M.R., Muhamad, N. and Khan, M.A. (2016). Influence of alkaline treatment and fiber loading composites than non-reinforced PP. The results confirmed MCC comprised of a higher percentage of cellulose I- $\beta$ structure and isotacticity of PP matrix. This research project prioritized importance of microcrystalline cellulose to reinforce PP matrix to prepare environmentally compatible bio composites.

on the physical and mechanical properties of kenaf/polypropylene composites for variety of applications Progress in Natural Science. Materials International. 26, 657-664.

Amir, N., Abidin, K.A.Z, and Shiri, F.B.M. (2017). Effects of Fibre Configuration on Mechanical Properties of Banana Fibre/PP/MAPP Natural Fibre Reinforced Polymer Composite. Procedia Engineering. 184, 573-580. 
Andreassen, E. (1999). Infrared and Raman spectroscopy of polypropylene. Polypropylene, 320-328

Begum, K. and Islam, M.A. (2013). Natural Fiber as a substitute to Synthetic Fiber in Polymer Composites: A Review. Research Journal of Engineering Sciences. 2(3), 46-53.

Bikiaris, D., Vassiliou, A., Chrissafis, K., Paraskevopoulos, K.M., Jannakoudakis, A. and Docoslis, A. (2008). Effect of acid treated multiwalled carbon nanotubes on the mechanical, permeability, thermal properties and thermo-oxidative stability of isotactic polypropylene. Polymer Degradation and Stability. 93, 952-967.

Canetti, M., Bertini, F., De Chirico, A. and Audisio, G. (2006). Thermal degradation behaviour of isotactic polypropylene blended with lignin. Polymer Degradation and Stability. 91, 494-498.

Joshi, S.V., Drzal, L.T., Mohanty, A.K. and Arora, S. (2004). Are natural fiber composites environmentally superior to glass fiber reinforced composites? Composites Part A. Applied Science and Manufacturing. 35, 371-376.

Kahawita, K.D.H.N., Samarasekara, A.M.P.B., Amarasinghe, D.A.S. and Karunanayake, L. (2018). Fabrication of Nanofibrillated Cellulose (NFC) Based Composite Materials for Engineering Applications. Proceedings of International Forestry and Environment Symposium. 56.

Kumar, N., Mireja, S., Khandelwal, V., Arun, B. and Manik, G. (2017). Light-weight high-strength hollow glass microspheres and bamboo fiber based hybrid polypropylene composite: A strength analysis and morphological study Composites Part B. Engineering. 109, 277-285.
Lee, K.Y., Aitomäki, Y., Berglund, L.A., Oksman, K. and Bismarck, A. (2014). On the use of nanocellulose as reinforcement in polymer matrix composites. Composites Science and Technology. $105,15-27$.

Liu, W., Ming-en Fei, M., Ban, Y., Jia, A. and Qiu, R. (2017). Preparation and Evaluation of Green Composites from Microcrystalline Cellulose and a Soybean-Oil. Derivative Polymers. 9( 541), 9-13.

Lu, P. and Hsieh, Y-L. (2010). Preparation and properties of cellulose nanocrystals: Rods, spheres, and network. Carbohydrate polymers. 82, 329-336.

Lu, Y., Tekinalp, H., Eberle, C.C., Peter, W., Naskar, A.K. and Ozcan, S. (2014). Nanocellulose in Polymer Composites and Biomedical Applications. Journal of Tappi. 13(6), 47-54.

Morent, R., De Geyter, N., Leys, C., Gengembre, L. and Payen, E. (2008). Comparison between XPS- and FTIR-analysis of plasma-treated polypropylene film surfaces: Surface and Interface Analysis. 40, 597-600.

Nanayakkara, M.P.A., Pabasara, W.G.A., Samarasekara, A.M.P.B., Amarasinghe, D.A.S. and Karunanayake, L. (2017). Extraction and Characterisation of Cellulose Materials from Sri Lankan Agricultural Waste. Proceedings of International Forestry and Environment Symposium. 47.

Poletto, M., Pistor, V. and Zattera, A.J. (2013). Structural Characteristics and Thermal Properties of Native Cellulose. IntechOpen. 45-65.

Rajapaksha, L.D., Saumyadi, H.A.D., Samarasekara, A.M.P.B., Amarasinghe, D.A.S. and Karaunanayake, L. (2017). Development of cellulose based light weight polymer composites. Moratuwa Engineering Research Conference (MERcon). 182-186. 
Sain, M., Suhara, P., Law, S. and Bouilloux, A. (2016). Interface Modification and Mechanical Properties of Natural Fiber-Polyolefin Composite Products. Reinforced Plastics and Composites. 24, 121-130.

Samarasekara, A.M.P.B., Anuradha, A.K. and De Zoysa, K.P.S. (2012a). Preparation of environmentally friendly photodegradable polymer blends using locally available raw materials. Proceedings of International Forestry and Environment Symposium. 54.

Samarasekara, A.M.P.B., Chamikara, A.W.C. and Wijesundara, W.W.H.P. (2014a). Extraction and Usage of Starch from Banana Pseudostem to Develop Biodegradable Polymer Composites. Proceedings of International Forestry and Environment Symposium. 60.

Samarasekara, A.M.P.B., Jayakody, J.D.C.M. and Madurasangani, A.G.S. (2012b). Study and development of low density polyethylene (LDPE) based biodegradable polymer materials using Kitul flour. Proceedings of International Forestry and Environment Symposium. 41.

Samarasekara, A.M.P.B. and Jayasuriya, E.A.P.C.D. (2014b). Synthesis of Biodegradable Polyolefins Based Polymer Composites Using Degradable Natural Materials. Proceedings of International Forestry and Environment Symposium. 61.
Samarasekara, A.M.P.B., Senavirathne, H.V.H.H. and Sandaruwan, A.H.W.O. (2012c). Preparation of biodegradable polymer materials using agricultural waste. Proceedings of International Forestry and Environment Symposium. 51.

Sofla, M.R.K., Brown, R.J., Tsuzuki, T. and Rainey, T.J. (2016). A comparison of cellulose nanocrystals and cellulose nanofibres extracted from bagasse using acid and ball milling methods Advances in Natural Sciences. Nanoscience and Nanotechnology. 7, 1-9.

Wang, L. and Sheng, J. (2005). Preparation and properties of polypropylene/orgattapulgite nanocomposites. Polymer. $46,6243-6249$.

Wei, L., Agarwal, U.P., Hirth, K.C., Matuana, L.M., Sabo, R.C. and Stark, N.M. (2017). Chemical modification of nanocellulose with canola oil fatty acid methyl ester. Carbohydrate polymers. $169,108-116$.

Zampaloni, M., Pourboghrat, F., Yankovich, S.A., Rodgers, B.N., Moore, J., Drzal, L.T., Mohanty, A.K. and Misra, M. (2007). Kenaf natural fiber reinforced polypropylene composites: A discussion on manufacturing problems and solutions Composites Part A. Applied Science and Manufacturing. 38, 1569-1580.. 